Arteterapia. Papeles de arteterapia y educación para inclusión social ISSN: $1886-6190$

\title{
Trauma y Arte (I)
}

\section{Nora Levinton Dolman}

Recibido: 16 de junio de 2016 / Aceptado: 26 de septiembre de 2016

Resumen. Volvemos a los orígenes de la cuestión del trauma en Psicoanálisis para revisar las condiciones en que surgieron las formulaciones que tanto peso tuvieron. Y los efectos que aún a día de hoy seguimos padeciendo ya que la actualidad reactiva todos los fantasmas con la abrumadora aparición de casos de abusos sexuales infantiles. La complicidad social que no termina de visibilizar, condenar y prevenir una lacra para la que apenas hay mención en las noticias de delitos. El artículo se propone revisitar el concepto de trauma desde una perspectiva actual integrando aportes de la neurociencia, la psicopatología del desarrollo y la neurobiología interpersonal. Y vincularlo a nuevos abordajes terapéuticos que permiten desbloquear esos fragmentos de recuerdos deconectados tan "siniestros" para el psiquismo para que alguna forma de integración sea posible.

Palabras clave: Trauma; Abusos sexuales infantiles; Nuevos aportes.

\section{[en] Trauma and Art (I)}

\begin{abstract}
We return to the origins of the issue of trauma in psychoanalysis to check the conditions in which the formulations emerged that much weight tuvieron.Y the effects even today continue to suffer because now all the ghosts reactive with the overwhelming appearance of cases of child sexual abuse. Social complicity that fails visible, condemn and prevent a scourge for which there is little mention in the news of crime. The article proposes to revisit the concept of trauma from a current perspective integrating contributions of neuroscience, developmental psychopathology and interpersonal neurobiology. And link it to new therapeutic approaches that allow unlock those disconnected fragments of memories looking for some way of integration possible.
\end{abstract}

Keywords: Trauma; Child sexual abuse; New contributions.

Sumario. 1. A modo de introducción; 2. El arte como terapia; 3. Referencias bibliográficas.

Cómo citar: Levinton Dolman, N. (2016) Trauma y Arte (I), en Arteterapia. Papeles de arteterapia y educación para inclusión social 11,355-363. 


\section{A modo de introducción}

La cuestión del trauma en psicoanálisis es un tema "radioactivo". Quema, genera efectos de largo alcance, promueve polémicas y reaparece inesperadamente.

Paradójicamente (¿o no?) encierra un pasado traumático ya que sus primeras conceptualizaciones sobre la histeria en 1896 habían llevado a Freud a formular la teoría de la seducción ${ }^{1}$ centrada en que la etiología de la histeria estaba vinculada a los efectos nocivos de experiencias sexuales infantiles de abuso. Explicación, la de la etiología sexual, que ponía de manifiesto la calidad traumática de esos sucesos. Lo que se creía olvidado, como tantas experiencias de la infancia, permanecía aletargado.

El trauma, bajo la forma de síntomas histéricos: disfonía, parálisis, cojera, dolores en diferentes articulaciones, desmayos, mareos, etc. eran la manifestación de un recuerdo reprimido como tal, pero potente en su actividad psíquica. ${ }^{2}$

En un segundo momento, cuando una nueva escena reactivaba el recuerdo de esas tempranas experiencias de seducción afloraba un síntoma histérico con la cualidad de sustituto de ese recuerdo.

El escenario donde todo esto sucedía era, Viena, y su ... fin de siècle.

Mucho se ha escrito sobre los motivos del cambio en la teoría, ya que se trató de un verdadero giro copernicano. La idea de que los abusos habían ocurrido realmente fue

recusada a favor de que eran fantasías, producto del mundo interno de las histéricas. Reproduciendo en ese sentido la opinión de la clase médica en general, las histéricas eran mentirosa, fabulaban y podían inventar cualquier tipo de coartadas para justificar sus síntomas.

La recepción de su conferencia en la Sociedad Psiquiátrica fue desfavorable, por decirlo tibiamente. Freud la describe en su carta a Fliess "como un recibimiento muy frío por parte de esos burros" (Masson, 1984) ${ }^{3}$, sintiéndose marginado y descalificado.

La transformación habilitó el desarrollo de conceptos primordiales en el psicoanálisis: el de realidad psíquica, la condición originaria y estructurante de la sexualidad infantil y la configuración edípica, el carácter traumático de la intensidad incestuoso infantiles que el paso del tiempo nos devuelve como un boomerang.

La clase médica hostil, tener que lidiar con que algunos de los padres o parientes de sus propias pacientes eran los abusadores, el temor de no seguir recibiendo pacientes cuando sus hipótesis trascendieran...un contexto turbio e incómodo, deben, a mi juicio, haber sido determinantes a la hora de la reformulación.

1 [...] en la base de todo caso de histeria se encuentran una o varias vivencias reproducibles por el trabajo analítico, no obstante que el intervalo pueda alcanzar decenios de experiencia sexual prematura, y pertenecientes a la tempranísima niñez. Estimo que esta es una revelación importante, el descubrimiento de un caput Nili de la neuropatología [...]Freud, Sigmund (1896). «II». La etiología de la histeria: Obras Completas, Vol. III (9a. edición). Buenos Aires: Amorrotu, 1996. p. 202.

ibidem

3 Jeffrey Masson,El asalto a la verdad: la renuncia de Freud a la teoría de la seducción, 1984. carta No. 139, 21 de septiembre de 1897. 


\subsection{El retorno de lo reprimido}

En el 2016, nos vemos abocadas a volver a considerar como "aquellas lluvias trajeron éstos lodos".

El abandono de la teoría de la seducción, trajo consecuencias nefastas en cuanto a desplazar la cuestión del abuso sexual infantil del epicentro de la psicopatología.

Resulta difícil no pensar que todo el conocimiento desplegado, los estudios y debates, las investigaciones académicas que han generado otros conceptos como el complejo de Edipo, el narcisismo, las consecuencias psíquicas de las diferencias anatómicas, e infinidad de títulos "sesudos", debería haber dado prioridad a un tema tan presente en todas las épocas.

Si hubiese generado una mayor resonancia en nuestra cultura sobre el peligro de los abusos sexuales infantiles, y debiera haber generado una potente alerta acompañado del peso de una sanción social extrema sobre los perpetradores.

Nos hemos pasado más de un siglo dando vueltas en torno al falo, en cualquiera de sus vertientes "epistémicas"...mientras millones de niñas y niños estaban siendo abusados.

Tanta teorización en torno al padre como ley, a su función de garantía de interdicción, de corte, etc. etc... como si el peligro temido viniese como no, de la mano (sic) de las pérfidas madres...cuando la realidad no deja de apabullarnos con los datos sobre la responsabilidad de padres, los biológicos y los así llamados porque la religión así los denomina, abuelos, tíos, padrastros, o sea: hombres.

Nuestra complicidad (en tanto psicoanalistas) con los peligros del abandono de la teoría de la seducción favoreció que la disociación como mecanismo de defensa, se haya disparado exponencialmente.

Cito a J.C.Volnovich:

Si la intervención de Freud en el siglo XX se jugó con la publicación del libro de los sueños y los tres ensayos para una teoría sexual; si el siglo XX nació conmovido por el escándalo que provocó la sexualidad infantil, el siglo XXI vuelve a movilizarse ante el escándalo de la sexualidad infantil. Sólo que, esta vez, la sexualidad infantil acusa su presencia travestida de "abuso sexual". Y no me refiero solamente a la literalidad del abuso (adultos que tienen relaciones sexuales con niños y con niñas, pornografía o prostitución infantil) sino al abuso perpetrado sobre el cuerpo de los niños por los medios de comunicación, las publicidades que inundan la ciudad, el Poder Judicial que para salvarlos los condena, en el mejor de los casos, al lugar de víctimas, los expertos que psicologizan el delito, el maltrato periodístico del abuso que se regodea en lo escabroso, y a otras formas subliminales de violencia que, por naturalizadas, se vuelven invisibles...

Porque el caso es que Freud no hizo nacer a la sexualidad infantil de un repollo ni supuso que la trajo la cigüeña. La sexualidad infantil se instaló en la huella que dejó abierta la teoría de la seducción. Fue necesario que la teoría de la seducción caducara para poder acceder al Complejo de Edipo, al concepto de trauma como posterioridad retroactiva. En última instancia, la sexualidad infantil como concepto teórico desplegado a 
partir de la renuncia a la teoría de la seducción significó un salto cualitativo, un progreso enorme para aquello que comenzó, entonces, a teorizarse como el "mundo interno". Pero, también -jcómo ignorarlo!pagó el precio de volver a invisibilizar el abuso sexual realmente cometido y a inocentizar a los perpetradores. Cuando Freud afirma que los relatos de abusos sexuales que poblaban su consulta eran producto de los deseos incestuosos de sus pacientes y no de acontecimientos reales, abre el camino a un campo inexplorado de investigación -la sexualidad perverso-polimorfa y la represión-, al tiempo que concede todo lo demás a los valores patriarcales dominantes. (Volnovich, 2005)

Escribo éste artículo cuando ya ha "corrido mucha agua bajo el puente". Hemos ampliado, haciendo mucho más exhaustiva la conceptualización sobre todo lo que puede convertirse en el desencadenante del trauma. El libro Trauma y cuerpo de Pat Odgen, Minton, K., Pain, C. (2009) nos ha proporcionado un material valiosísimo.

Ya sabemos que la mayoría de los traumas tienen lugar dentro del contexto de las relaciones interpersonales, lo que implica que el trauma incluye violaciones de los límites (personales), pérdida de la acción autónoma y de la propia capacidad de regulación. Cito:

"La esencia de la traumatización es la indefensión más absoluta combinada con el abandono por parte de los cuidadores supuestamente protectores. ${ }^{5}$ (Ogden, 2009).

Pero también la realidad sigue "aportando" infinitas causas, las guerras, los desplazamientos de millones de personas buscando un refugio, a los que paradójicamente se intenta llamar refugiados. Los golpes militares y la lacra de desaparecidos, asesinatos de todo tipo y condición, la crueldad desplegada en las torturas, las masacres, y un terriblemente infinito etcétera. Y en un epígrafe particular toda la parafernalia desplegada específicamente contra las mujeres, por el hecho de serlo: las violaciones, diferentes tipos de mutilaciones, los matrimonios y embarazos forzados, la trata de mujeres...Un estremecedor imaginario de vulnerabilidad para despertar todos nuestros fantasmas de inseguridad. La naturaleza recordándonos su potencia ilimitada, los terremotos, inundaciones, tsunamis, huracanes...los ejemplos serían inacabables.

Una fuerza poderosísima frente a nuestro frágil psiquismo. Una lucha desigual en la que literalmente se nos va la vida, la salud, la tranquilidad, el bienestar...la posibilidad de confiar en nuestra capacidad de sobrevivir, de autoregularnos...

4 Volnovich, J.C. Para releer a Freud: cien años de los Tres Ensayos para una teoría sexual Topía.

5 Presentación de Trauma y cuerpo. Odgen, P., Minton, K., Pain, C. (2009)

Bilbao; Ed. Desclée de Brouwer en el Taller de Psicoterapia con orientación de género. 


\subsection{Sobre la Disociación}

Uno de los aportes más lúcidos al tema del trauma, lo hizo en $1932{ }^{6}$ Sandor Ferenczi que había explicado cómo la "identificación con el agresor", puede ser una respuesta frente a los traumas. Y revisitando éste concepto, Jay Frankel escribió un artículo que siempre me ha parecido un prodigio de claridad y síntesis. Escribe sobre los efectos del trauma:

"La resultante en el psiquismo es que, desbordado por el temor a una amenaza que vive como ineludible, transforma su conducta, incluso sus pensamientos, percepciones y emociones.

«He aquí el concepto de Ferenczi: explorando los recuerdos tempranos de sus pacientes adultos que sufrieron abusos siendo niños, Ferenczi $(1933)^{7}$ halló evidencias de que los niños que son aterrorizados por adultos que están fuera de control, se someterán como autómatas a la voluntad del agresor para adivinar cada uno de sus deseos y gratificarlos; completamente olvidados de sí mismos, se identifican con el agresor... La personalidad débil y poco desarrollada reacciona al displacer súbito no con defensas, sino con una identificación guiada por la ansiedad y por introyección del agresor o persona amenazante" (pp. 162-163, el pasaje completo figura en cursiva en el original - sic -). El niño "deviene uno" (p.165) con el atacante». (Frankel, 2002, p.2). ${ }^{8}$

...El objetivo es "hacer desaparecer" el propio self, dejar de ser quien se es para poder desempeñar el papel que el otro, la figura que representa algún tipo de autoridad temida, espera que seamos, incluyendo este aspecto que tanto daño psíquico puede producir: la introyección de los sentimientos de culpa.

Ferenczi describe así tres movimientos propios de este proceso de respuesta a la agresión

- En un primer momento, por miedo (angustia persecutoria) sobreviene

- En $2^{\circ}$ término, a partir del sometimiento hay un esfuerzo por tratar de "adivinar" los deseos del agresor, lo que podría considerarse una hipervigilancia selectiva para garantizar la propia supervivencia y

- En $3^{\circ}$ lugar ya aparece la falsificación del "sí mismo", para protegerse a través de la sumisión y la complacencia. Lo cual queda explicado como:

6 - Ferenczi, S. (1932). The Clinical Diary of Sándor Ferenczi, ed. J. Dupont. (trans. M. Balint \& N. Z. Jackson). Cambridge, MA: Harvard University Press, 1988. Citado en Frankel, J. Explorando el concepto de Ferenczi de identificación con el agresor. Su rol en el trauma, la vida cotidiana y la relación terapéutica. Aperturas Psicoanalíticas, 11, 2002 (www.aperturas.org)

7 Ferenczi, S. (1933) Confusión of tongues between adults and the child. En: Final Contributions to the Problems and Methods of Psycho-Analysis, ed. M. Balint (trans. E. Mosbacher). London: Karnac Books

8 Frankel, J. Explorando el concepto de Ferenczi de identificación con el agresor. Su rol en el trauma, la vida cotidiana y la relación terapéutica. Aperturas Psicoanalíticas, 11, 2002 (www.aperturas.org) 
«la autoconciencia es un gran peligro, por eso puede ser más fácil erigir una barrera contra la percepción o el conocimiento de algo que prevenirse a uno mismo para no decir algo que se sabe. El resultado es que la persona traumatizada construye una narrativa privada de su vida que deja fuera algunas cosas y exagera otras.... La disociación y la identificación con el agresor trabajan juntas, coordinadas, sosteniéndose mutuamente... En el momento del trauma, la disociación vacía la mente de la propia experiencia, incluyendo percepciones, pensamientos y la sensación de vulnerabilidad... la disociación de la experiencia emocional puede desempeñar dos funciones: primero, nos aleja de la insoportable vivencia del dolor o del miedo; segundo nos ayuda en nuestra adaptación aislando selectivamente sólo aquellos sentimientos que pudieran ser una amenaza en la situación inmediata si fueran expresados» ${ }^{9}$.

Todo queda magistralmente descrito.Nos ofrece una lectura detallada del escenario. Explica paso a paso como puede entenderse el efecto traumático de ésta identificación en las personas que han sufridos malos tratos y/o abusos sexuales en la niñez.

Esa suplantación de su propia percepción por la del agresor, una hiperadaptación para garantizar la supervivencia al precio de la anulación de la conexión, de la pérdida de confianza en sus impresiones para adoptar las del depredador.

Fue un trabajo pionero. Esclarecedor, que iluminó un contexto poco explorado.

Mucho antes de que las nuevas disciplinas: ${ }^{10}$

- Neurociencias: y cómo el cerebro soporta los procesos mentales

- Psicopatología del desarrollo: y el estudio del impacto de las emociones negativas en el desarrollo de la mente y del cerebro

- Neurobiología interpersonal: y cómo influye nuestro comportamiento en las emociones, la biología y la mentalidad de la gente que nos rodea

lo terminaran de ratificar, a través de pruebas empíricas.

Por eso Van der Kolk insistirá sobre la necesidad de considerar que el trauma "no es solo un acontecimiento que se produjo en algún momento del pasado; también es la huella dejada por una experiencia en la mente, el cerebro y el cuerpo. Éstas huellas tienen consecuencias permanentes sobre el modo en que el organismo humano logra sobrevivir en el presente. El trauma genera una reorganización fundamental del manejo de las percepciones por parte de la mente y el cerebro. Cambia no solo cómo y en qué pensamos, sino también nuestra propia capacidad de pensar." 11 (pág.23)

Las investigaciones realizadas sobre la biología de los recuerdos traumáticos nos permiten entender tanto mejor y por ende buscar otros recursos para poder enfrentar el reto del abordaje terapéutico.

\footnotetext{
$9 \quad$-Id.

10 Van der Kolk, Bessel (2016) EL CUERPO LLEVA LA CUENTA: CEREBRO, MENTE Y CUERPO EN LA SUPERACION DEL TRAUMA. ELEFTHERIA. ISBN 9788494408403

11 Idem
} 
La lacra de la violencia contra las mujeres nos llevó a tener que profundizar en el tema de las consecuencias que acarreaba sobre su psiquismo. A investigar sobre indefensión aprendida o sea la incapacidad de intentar respuestas de defensa, básicamente luchar o escapar, útiles.

A la reacción de bloqueo, como una manera de rendirse al miedo que las inunda.

Por eso también nos resultó de un valor inestimable saber que las personas traumatizadas siguen secretando grandes cantidades de la hormona del estrés mucho tiempo después del peligro real, porque el sistema de alerta ${ }^{12}$ está deteriorado y siguen activas las señales de lucha, huida o paralización, lo que daña considerablemente el sistema inmunológico. Aclara Van der Kolk:

"Mi experiencia con los veteranos de guerra me había sensibilizado tanto ante el impacto del trauma que ahora escuchaba de un modo muy distinto a los pacientes deprimidos y con ansiedad que me contaban sus historias de abusos sexuales y violencia familiar. En especial, me sorprendía la cantidad de pacientes femeninas frecuente en Estados Unidos, y que solo ocurría a una de cada millón de mujeres. Teniendo en cuenta que solo había unos cien millones de mujeres en aquella época viviendo en Estados Unidos, me preguntaba como cuarenta y siete, casi la mitad, se las había apañado para encontrar mi consulta en el sótano del hospital. Además, los manuales decían 'Existe poco consenso sobre el papel del incesto padre-hija como fuente de una psicopatología subsiguiente grave'. Mis pacientes con historias de incestos estaban lejos de no sufrir una «psicopatología subsiguiente«: estaban profundamente deprimidas, confusas y a menudo incurrían en comportamientos extrañamente autolesivos, como cortarse con hojas de afeitar. Los libros seguían prácticamente respaldando el incesto, explicando 'que ésta actividad incestuosa reduce la posibilidad de sufrir psicosis por parte del sujeto y permite un mejor ajuste al mundo exterior'.En realidad, sin embargo resultaba que el incesto tenía unos efectos devastadores en el bienestar de las mujeres.

En muchos sentidos, estas pacientes no eran tan diferentes de los veteranos que acababa de dejar atrás en la clínica de la VA. También tenían pesadillas y flashbacks. También alternaban entre ataques ocasionales de rabia explosiva y largos períodos de desconexión emocional. La mayoría de ellas había tenido muchos problemas de relación con los demás y les costaba mantener relaciones serias.

\section{El arte como terapia}

La búsqueda de otros dispositivos terapéuticos fue abriéndose camino.

Afortunadamente el momento actual nos ofrece otras alternativas para posibilitar "el procesamiento a través del cuerpo, de los recuerdos implícitos y los efectos neurobiológicos del trauma. Basándose en el desarrollo y contribuciones de la neurociencia, el estudio del trauma y la disociación y la teoría del apego, la terapia sensoriomotriz sitúa la experiencia corporal, como el elemento central

12 Sapolsky, R. ¿Por qué las cebras no tienen úlcera?. Alianza Editorial, 2008. 
desde donde abordar el trauma. A diferencia de las psicoterapias tradicionales, que tratan de recuperar "la historia olvidada" y procesar la experiencia de forma "descendente", es decir, de arriba a abajo, desde las cogniciones y emociones hasta las vivencias corporales, la terapia sensoriomotriz propone una intervención inversa, " ascendente", esto es, a través de la autoobservación y el trabajo con el cuerpo, provocar un cambio significativo en los pensamientos, emociones, sistemas de creencias y pautas de acción fijas asociados al padecimiento de una experiencia traumática." $" 13$

También programas específicos de danza, de teatro, de formas de expresión a través del movimiento. El arteterapia buscando poner en palabras, en arcilla, en colores, en un pentagrama, en una coreografía ese resto de un dolor que permanece... tal vez aún no representado. ¿Es la herida?, ¿El miembro ausente?

Conseguir transformar a partir de la reminiscencia dolorosa, ¿o sería mejor decir con ella?, de esos fragmentos dislocados e incongruentes, un objeto con toda la polisemia que el concepto ofrece que favorezca algún tipo de alivio, literalmente, un aligeramiento de la carga o peso.

Encontrar un medio, un enlace entre una textura y una sensibilidad que encuentra el material adecuado para canalizar allí algo de su miedo.

Una técnica que provee de un medio para que emerja una vía de facilitación a una emoción que no puede ponerse en palabras, a una contractura congelada en el cuerpo que obliga a repetir un movimiento doloroso, a una desconfianza que no se identifica como tal.

Crear un habitat donde la yema de los dedos, puedan ser la oportunidad de salir de ese particular infierno personal.

Un ecosistema personal e intransferible donde un dibujo, un poema, una performance consigan horadar la médula de lo que no se termina de recordar ni de olvidar.

Querría finalizar con Margaret Atwood, que consigue traducir en éste poema, exactamente esa posibilidad en que el arte, en éste caso a través de las palabras tiende un puente para que un dolor pueda ser escuchado.

\section{Luna nueva}

La oscuridad espera desde cualquier ocasión que surja;

como la pena que siempre está disponible

Ésta es sólo un modelo, el modelo en el que hay estrellas

sobre las hojas, brillantes como clavos de acero

e incontables y sin que se las haga caso.

Caminamos juntos

sobre hojas muertas

húmedas en la luna nueva

entre las rocas nocturnas amenazadoras

que serían de un gris rosado

a la luz del día, roídas y suavizadas

13 Terapia Sensoriomotor.Fernando Sánchez Rodríguez. Revista Digital de Medicina Psicosomática y Psicoterapia. S.E.M.P. y P. ISSN: 2253-749X Vol. 3 (2013) n. ${ }^{\circ} 2$ 
por el musgo y los helechos, que serían verdes

en el olor mohoso a levadura fresca

de árboles que enraízan, la tierra devuelve

lo mismo a lo mismo,

y cojo tu mano, que tiene el aspecto que tendría

una mano si de veras existieras.

Deseo mostrarte la oscuridad

que tanto temes.

Confía en mí. Esta oscuridad

es un lugar al que puedes entrar y sentirte

tan seguro como en cualquier otra parte;

puedes poner un pie delante del otro

y creer a los lados de tus ojos.

Memorízalo. Lo sabrás

de nuevo cuando te corresponda.

Cuando la apariencia de las cosas te haya abandonado,

todavía tendrás esta oscuridad.

Algo propio que puedes llevar contigo.

Hemos llegado al borde:

el lago entrega su silencio;

en la noche exterior hay un búho

cantando, como una polilla

en la oreja, desde la costa lejana

que es invisible.

El lago, vasto y sin dimensiones, repite todo, las estrellas,

las piedras, a sí mismo, incluso la oscuridad

en la que puedes caminar

hasta que se convierta en luz.

Margaret Atwood (1984)

\section{Referencias bibliográficas}

Atwood, M. Luna Nueva (Icaria, 2000). ISBN 9788474264166

Atwood, M. Luna Nueva (Icaria, 2000). ISBN 9788474264166

Freud, Sigmund (1896). «II». La etiología de la histeria: Obras Completas, Vol. III (9a. edición). Buenos Aires: Amorrotu, 1996. p. 202.

Jeffrey Masson El asalto a la verdad: la renuncia de Freud a la teoría de la seducción, 1984. carta No. 139, 21 de septiembre de 1897.

Terapia Sensoriomotor. Fernando Sánchez Rodríguez. Revista Digital de Medicina Psicosomática y Psicoterapia. S.E.M.P. y P. ISSN: 2253-749X Vol. 3 (2013) n. ${ }^{\circ} 2$

Van der Kolk, Bessel (2016) El cuerpo lleva la cuenta: cerebro, mente y cuerpo en la superacion del trauma. ELEFTHERIA. ISBN 9788494408403

Volnovich, J.C. Para releer a Freud: cien años de los Tres Ensayos para una teoría sexual. Revista Topía. 